\title{
Agreeableness, Extraversion, Stressor and Physiological Stress Response
}

\author{
Xiaoyuan $\mathrm{Chu}^{1}$, Zhentao $\mathrm{Ma}^{2}$, Yuan $\mathrm{Li}^{3}$ \& Jing $\mathrm{Han}^{1}$ \\ ${ }^{1}$ School of Economics and Resource Management, Beijing Normal University, Beijing, China \\ ${ }^{2}$ School of Government, Beijing Normal University, Beijing, China \\ ${ }^{3}$ Research Department, CIConsulting, Shenzhen, China \\ Correspondence: Xiaoyuan Chu, School of Economics and Resource Management, Beijing Normal University, Beijing, \\ China. Tel +8613126756090
}

Received: May 12, 2015

Accepted: May 27, 2015

Available online: June 4, 2015

doi:10.11114/ijsss.v3i4.857

URL: http://dx.doi.org/10.11114/ijsss.v3i4.857

\begin{abstract}
Based on the theoretical analysis, with first-hand data collection and using multiple regression models, this study explored the relationship between agreeableness, extraversion, stressor and stress response and figured out interactive effect of agreeableness, extraversion, and stressor on stress response. We draw on the following conclusions: (1) the interaction term of stressor (work) and agreeableness can negatively predict physiological stress response; (2) the interaction term of stressor (health) and agreeableness can negatively predict physiological stress response; (3) the interaction term of stressor (family) and agreeableness can negatively predict physiological stress response; (4) the interaction term of stressor (social) and agreeableness can negatively predict physiological stress response; (5) the interaction term of stressor (work) and extraversion can negatively predict physiological stress response; (6) the interaction term of stressor (health) and extraversion can negatively predict physiological stress response; (7) the interaction term of stressor (family) and extraversion can negatively predict physiological stress response; (8) the interaction term of stressor (social) and extraversion can negatively predict physiological stress response.
\end{abstract}

Keywords: Agreeableness, Extraversion, Physiological Stress Response, Interaction Effect

\section{Introduction}

Agreeableness is defined as the tendency to be good-natured and cooperative (Costa \& McCrae, 1992). Evidence suggests a link between agreeableness and the processing of conflict engendered by discrepant person-environment fit (Tobin et al., 2000). Individuals high in agreeableness show higher tendency of forgiveness (Cao et al. 2006). Studies in Portuguese population show that agreeableness and forgiveness are significantly positively correlated (Lee et al, 2005). Some research also indicates agreeableness positively correlated with stressor-evoked blood pressure reactivity (Ryan, et al, 2011) and it significantly influences the daily stress and coping process, though mainly in the context of daily interpersonal events (Hettler \& Tanya, 2001). In addition, agreeableness can be used to predict SWB (De Neve \& Cooper, 1998) as well as stress response, especially physiological stress response, which includes tiredness; discomforts such as headache, tightness and tinnitus; loss of appetite; poor sleep status (Chu et al, 2015).

Extraversion is an indicator of extrovert personality. It includes a wide range of personality traits of social, talkative, decisive, ambitious and passionate. Studies have shown that high extraversion and positive emotion correlated with each other (Canli et al, 2001; Amin, Constable \& Canli, 2004; Jeffrey \& Jaak, 2006). For example, individuals who got higher scores on extraversion report more positive emotional experience in their daily lives, and this helps to anticipate their positive emotional experience after 10 years (Costa \& McCrae, 1980, 1990). There are several reasons for this phenomenon. First of all, outgoing individuals are sensitive to positive stimulation (Yuan et al, 2007). Secondly, outgoing individuals tend to pay attention to positive stimulation (Derryberry \& Reed, 1994; Huang \& Luo, 2006), which almost happens automatically (Yuan et al, 2007; Huang \& Luo, 2007). Similarly, studies have shown that high extraversion and life satisfaction are correlated, and extroversion can improve SWB (McCrae \& John, 1992); high extraversion and job stress and burnout were significantly negatively correlated (Mills \& Huebner, 1998; Bakker, Zee \& Lewig, 2006); extraversion has a positive effect on stress response (Chu et al, 2015; Schneider, 2012).

On the basis of previous studies, this study attempts to use primary and secondary school teachers as subjects, investigating the relationship among agreeableness, extraversion, stressor and physiological stress responses, trying to 
discover the underlining mechanisms.

In order to reveal the relationship between agreeableness, extraversion, stressors and physiological stress responses, this paper constructed a basic model as follows:

$$
\begin{aligned}
& P R_{i}=\beta_{0}+\sum \lambda_{1 j} \text { Stressor }_{j i}+\lambda_{2} \text { Agreeableness }_{i}+\sum \lambda_{3 j} \text { Stressor }_{j i} * \text { Agreeableness }_{i}+\varepsilon_{i} \\
& P R_{i}=\beta_{0}+\sum \lambda_{1 j} \text { Stressor }_{j i}+\lambda_{2} \text { Extraversion }_{i}+\sum \lambda_{3 j} \text { Stressor }_{j i} * \text { Extraversion }_{i}+\varepsilon_{i}
\end{aligned}
$$

In the formula, i represents the subjects, $\mathrm{j}$ represents the type of stressors, PR represents physiological stress response, Stressor represents pressure source (including work stress, health stress, family stress and social stress), Stressor ${ }_{\mathrm{ji}}{ }^{*}$ Extraversion $_{\mathrm{i}}$ as well as Stressor ${ }_{\mathrm{ji}}{ }^{*}$ Agreeableness $\mathrm{i}_{\mathrm{i}}$ is the interaction term, and $\varepsilon \mathrm{i}$ is the error term. And we would test whether the interaction terms $\left(\right.$ Stressor $_{\mathrm{ji}}{ }^{*}$ Extraversion $_{\mathrm{i}}$ and Stressor $_{\mathrm{ji}}{ }^{*}$ Agreeableness $\mathrm{i}_{\mathrm{i}}$ ) would have significant predictive effects on physiological stress response.

\section{Research Methods}

\subsection{Subjects}

460 primary and secondary school teachers were recruited as subjects and 432 questionnaires were returned. After excluding invalid questionnaires, we finally obtained 428 valid questionnaires. The valid response rate is $93.04 \%$. The basic information of the sample is in Table 1 as below.

\subsection{Research Instrument}

\subsubsection{Agreeableness and Extraversion}

Big Five Personality Inventory, namely NEO-Personality Inventory is used to measure agreeableness and extraversion. This scale is based on the Big Five personality theory and was compiled by the American psychologist Costa Costa and McCrae McRae in 1987. After many years of use and revision, this scale has been of high reliability and validity. The scale uses five scoring system, whose range of scores is 1 to 5 points. Scoring higher or lower indicates some more obvious characteristic in agreeableness and extraversion.

\subsubsection{Stressor and Stress Response.}

Work Stress Scale for Primary and Secondary School Teacher was used to measure stressor and stress response in this study. The scale consists of two parts. The first part is the source of stress, including a total of 36 items in four dimensions. The four dimensions are: work stress, health stress, family stress and social stress. The second part is the stress response with physiological stress response included. It has been testified that the liability and validity of the scale are good. Specifically, the scale uses five scoring system, whose range of scores is 0 to 4 points. Scoring higher or lower indicates some more obvious characteristics in certain aspects.

\subsection{Research Process}

The questionnaires were administrated with the unified instructions. And the questionnaires, with no time limitation, were collected on the spot and checked one by one with invalid ones eliminated. This research employed SPSS19.0 for statistical analysis, which includes analysis of variance, correlation analysis and analysis of regression.

Table 1. Basic Information of the Sample and the F-test for the Stress Response

\begin{tabular}{cccccc}
\hline $\begin{array}{c}\text { Demographic } \\
\text { Variable }\end{array}$ & & $\mathrm{N}$ & Percentage & $\begin{array}{c}\text { Statistical } \\
\text { value }\end{array}$ & $\begin{array}{c}\text { Physiological } \\
\text { Stress Response }\end{array}$ \\
\hline Marital status & Unmarried & 85 & 20.4 & & $8.22 \pm 3.704$ \\
& Married & 323 & 77.5 & & $8.77 \pm 3.777$ \\
& Divorced & 9 & 2.2 & & $10.25 \pm 3.732$ \\
& & & & & \\
& & & & F & 1.41 \\
& & & & P & 0.245
\end{tabular}




\begin{tabular}{|c|c|c|c|c|c|}
\hline \multirow[t]{5}{*}{$\begin{array}{l}\text { Types } \\
\text { School }\end{array}$} & $\begin{array}{l}\text { Elementar } \\
\mathrm{y}\end{array}$ & 154 & 38.1 & & $10.16 \pm 3.733$ \\
\hline & $\begin{array}{l}\text { Junior } \\
\text { High }\end{array}$ & 77 & 19.1 & & $7.89 \pm 3.486$ \\
\hline & $\begin{array}{l}\text { Senior } \\
\text { High }\end{array}$ & 173 & 42.8 & & $7.66 \pm 3.423$ \\
\hline & & & & F & 22.082 \\
\hline & & & & $\mathrm{P}$ & 0.000 \\
\hline \multirow[t]{6}{*}{ Service Year } & $\leq 5$ & 71 & 17 & & $8.07 \pm 3.969$ \\
\hline & $5<\leq 10$ & 146 & 35 & & $8.21 \pm 3.472$ \\
\hline & $10<\leq 20$ & 144 & 34.5 & & $9.01 \pm 4.022$ \\
\hline & $>20$ & 56 & 13.4 & & $9.88 \pm 3.390$ \\
\hline & & & & $\mathrm{F}$ & 3.636 \\
\hline & & & & $\mathrm{P}$ & 0.013 \\
\hline \multirow[t]{4}{*}{ Child(ren) } & With & 236 & 66.5 & & $8.86 \pm 3.81$ \\
\hline & Without & 119 & 33.5 & & $8.14 \pm 3.379$ \\
\hline & & & & F & 3.063 \\
\hline & & & & $\mathrm{P}$ & 0.081 \\
\hline \multirow[t]{4}{*}{ Gender } & Male & 97 & 23.4 & & $8.19 \pm 3.756$ \\
\hline & Female & 317 & 76.6 & & $8.81 \pm 3.78$ \\
\hline & & & & F & 2.01 \\
\hline & & & & $\mathrm{P}$ & 0.157 \\
\hline
\end{tabular}

\section{Results}

3.1 Correlation Analysis of Agreeableness, Extraversion, Stressors and Physiological Stress Response

A correlation analysis of the stressors and physiological stress response was conducted. As shown in Table 2, all the dimensions of stressor are significantly positively correlated with physiological stress response. And the correlation analysis of agreeableness, extraversion and physiological stress response found that extraversion is negatively correlated with the physiological stress response while no significant correlation was found between agreeableness and physiological stress response.

Table 2. Correlation Matrix of Variables

\begin{tabular}{|c|c|c|c|c|c|c|c|}
\hline Variable & 1 & 2 & 3 & 4 & 5 & 6 & 7 \\
\hline 1 Extraversion & 1 & & & & & & \\
\hline 2 Agreeableness & $.494 * *$ & 1 & & & & & \\
\hline 3 Stressor (work) & $-.213^{* *}$ & $-.223^{* *}$ & 1 & & & & \\
\hline
\end{tabular}




\begin{tabular}{llllllll}
\hline 4 Stressor (health) & -.061 & $-.193^{* *}$ & $.643^{* *}$ & 1 & & & \\
5 Stressor (family) & $-.182^{* *}$ & -.087 & $.457^{* *}$ & $.285^{* *}$ & 1 & & \\
6 Stressor (social) & $-.198^{* *}$ & $-.153^{* *}$ & $.591^{* *}$ & $.337^{* *}$ & $.418^{* *}$ & 1 & \\
7 Physiological Stress Response & $-.115^{*}$ & -.088 & $.476^{* *}$ & $.447^{* *}$ & $.352^{* *}$ & $.382^{* *}$ & 1 \\
Minimum & 33 & 20 & .05 & 0 & 0 & 0 & 0 \\
Maximum & 72 & 71 & 3.48 & 4.00 & 4.00 & 4.00 & 4.00 \\
Mean & 50.72 & 55.71 & 1.83 & 1.70 & 1.67 & 2.13 & 1.73 \\
\hline
\end{tabular}

\subsection{Regression Analysis of Agreeableness, Stressors on Physiological Stress Response}

In order to understand the combined effect of stressors and agreeableness on physiological stress response, we take physiological stress response as the predicted variable, and stressor (work), stressor (health), stressor (family), stressor (social), agreeableness and interaction terms of agreeableness and above-mentioned stressors as the predictive variables to do the regression analysis. The analysis results are shown in Table 3.

As shown in Table 3, model 1 indicates that three out of the four stressors (health, family and social) are significant predictors in physiological stress response regression model; Model 2 indicates that in consideration of the stressors but not interactive terms, agreeableness is not significant in physiological stress response regression model; Model 3 indicates that in physiological stress response regression model, agreeableness has a significant interactive effect with stressor (work); Model 4 indicates that in physiological stress response regression model, agreeableness has a significant interactive effect with stressor (health); Model 5 indicates that in physiological stress response regression model, agreeableness has a significant interactive effect with stressor (family); Model 6 indicates that in physiological stress response regression model, agreeableness has a significant interactive effect with stressor (social).

Table 3. Agreeableness, Stressors and Physiological Stress Response (Predicted variable: Physiological Stress Response)

\begin{tabular}{|c|c|c|c|c|c|c|}
\hline Predictive variable & Model 1 & Model 2 & Model 3 & Model 4 & Model 5 & Model 6 \\
\hline \multirow[t]{2}{*}{ Agreeableness } & & .019 & $.372 * *$ & $.244 * *$ & $.180^{*}$ & .139 \\
\hline & & $(.455)$ & (2.994) & $(2.638)$ & $(2.175)$ & (1.377) \\
\hline \multirow[t]{2}{*}{ Stressor (work) } & .124 & .127 & $1.218 * * *$ & & & \\
\hline & $(1.913)$ & $(1.952)$ & $(4.987)$ & & & \\
\hline \multirow[t]{2}{*}{ Stressor (health) } & $.267 * * *$ & $.269 * * *$ & & $1.240 * * *$ & & \\
\hline & (4.958) & $(4.972)$ & & $(4.821)$ & & \\
\hline \multirow[t]{2}{*}{ Stressor (family) } & $.136 * *$ & $.135 * *$ & & & $1.363 * * *$ & \\
\hline & $(2.820)$ & $(2.802)$ & & & $(4.818)$ & \\
\hline \multirow{2}{*}{ Stressor (social) } & $.177 * *$ & $.177 * *$ & & & & $.971 * *$ \\
\hline & $(3.367)$ & $(3.371)$ & & & & $(3.386)$ \\
\hline \multirow[t]{2}{*}{ Agreeableness*Stressor (work) } & & & $-.772 * *$ & & & \\
\hline & & & $(-3.142)$ & & & \\
\hline \multirow[t]{2}{*}{ Agreeableness*Stressor (health) } & & & & $-.801 * *$ & & \\
\hline & & & & $(-3.155)$ & & \\
\hline \multirow[t]{2}{*}{ Agreeableness*Stressor (family) } & & & & & $-1.043 * * *$ & \\
\hline & & & & & $(-3.658)$ & \\
\hline \multirow[t]{2}{*}{ Agreeableness*Stressor (social) } & & & & & & $-.592 *$ \\
\hline & & & & & & $(-2.053)$ \\
\hline \multicolumn{7}{|l|}{ Control variable } \\
\hline Gender & .083 & .082 & .054 & .074 & $.128 * *$ & $.103 *$ \\
\hline
\end{tabular}




\begin{tabular}{lllllll}
\hline & $(1.959)$ & $(1.913)$ & $(1.230)$ & $(1.677)$ & $(2.801)$ & $(2.277)$ \\
Age & $.150 * * *$ & $.149^{* *}$ & $.133^{* *}$ & $.133^{* *}$ & $.102 *$ & $.183 * * *$ \\
& $(3.519)$ & $(3.489)$ & $(3.048)$ & $(3.036)$ & $(2.217)$ & $(3.988)$ \\
$\mathrm{R} 2$ & .315 & .315 & .254 & .239 & .176 & .190 \\
Adjusted R2 & .304 & .303 & .245 & .230 & .166 & .180 \\
$\mathrm{~N}$ & 412 & 412 & 412 & 412 & 412 & 412 \\
\hline
\end{tabular}

Note: $* * *, * *$ and $*$ indicate that the coefficient is significant at the $0.01,0.05$ and 0.1 levels, respectively the same below.

\subsection{Regression Analysis of Extraversion, Stressors on Physiological Stress Response}

In order to understand the combined effect of stressors and extraversion on physiological stress response, we take physiological stress response as the predicted variable, and stressor (work), stressor (health), stressor (family), stressor (social), extraversion and interaction terms of extraversion and above-mentioned stressors as the predictive variables to do the regression analysis. The analysis results are shown in Table 4.

As shown in Table 4, model 1 indicates that three out of the four stressors (health, family and social) are significant predictors in physiological stress response regression model; Model 2 indicates that in consideration of the stressors but not interactive terms, the extraversion is not significant in physiological stress response regression model; Model 3 indicates that in physiological stress response regression model, extraversion has a significant interactive effect with stressor (work); Model 4 indicates that in physiological stress response regression model, extraversion has a significant interactive effect with stressor (health); Model 5 indicates that in physiological stress response regression model, extraversion has a significant interactive effect with stressor (family); Model 6 indicates that in physiological stress response regression model, extraversion has a significant interactive effect with stressor (social).

Table 3. Agreeableness, Stressors and Physiological Stress Response (Predicted variable: Physiological Stress Response)

\begin{tabular}{|c|c|c|c|c|c|c|}
\hline Predictive variable & Model 1 & Model 2 & Model 3 & Model 4 & Model 5 & Model 6 \\
\hline \multirow[t]{2}{*}{ Extraversion } & & -.022 & $.330^{*}$ & .111 & .083 & .188 \\
\hline & & $(-.509)$ & $(2.423)$ & (1.114) & $(1.044)$ & $(1.791)$ \\
\hline \multirow[t]{2}{*}{ Stressor (work) } & .124 & .119 & $1.303 * * *$ & & & \\
\hline & $(1.913)$ & $(1.819)$ & (4.196) & & & \\
\hline \multirow[t]{2}{*}{ Stressor (health) } & $.267 * * *$ & $.269 * * *$ & & $1.126^{* * *}$ & & \\
\hline & $(4.958)$ & $(4.979)$ & & (3.716) & & \\
\hline \multirow[t]{2}{*}{ Stressor (family) } & $.136^{* *}$ & $.134 * *$ & & & $1.054 * *$ & \\
\hline & $(2.820)$ & $(2.770)$ & & & $(3.356)$ & \\
\hline \multirow[t]{2}{*}{ Stressor (social) } & $.177 * *$ & $.175^{* *}$ & & & & $1.211^{* * *}$ \\
\hline & $(3.367)$ & $(3.329)$ & & & & $(3.702)$ \\
\hline \multirow[t]{2}{*}{ Extraversion*Stressor (work) } & & & $-.851 * *$ & & & \\
\hline & & & $(-2.757)$ & & & \\
\hline \multirow[t]{2}{*}{ Extraversion*Stressor (health) } & & & & $-.713^{*}$ & & \\
\hline & & & & $(-2.302)$ & & \\
\hline \multirow[t]{2}{*}{ Extraversion*Stressor (family) } & & & & & $-.715^{*}$ & \\
\hline & & & & & $(-2.313)$ & \\
\hline \multirow[t]{2}{*}{ Extraversion*Stressor (social) } & & & & & & $-.821 *$ \\
\hline & & & & & & $(-2.547)$ \\
\hline \multicolumn{7}{|l|}{ Control variable } \\
\hline Gender & .083 & $.084^{*}$ & .052 & .075 & $.115^{*}$ & $.091^{*}$ \\
\hline
\end{tabular}




\begin{tabular}{lllllll}
\hline & $(1.959)$ & $(1.978)$ & $(1.178)$ & $(1.714)$ & $(2.468)$ & $(2.010)$ \\
Age & $.150 * * *$ & $.151 * * *$ & $.137 * *$ & $.141 * *$ & $.105 *$ & $.184 * * *$ \\
& $(3.519)$ & $(3.532)$ & $(3.140)$ & $(3.206)$ & $(2.270)$ & $(4.026)$ \\
$R^{2}$ & .315 & .315 & .250 & .239 & .159 & .195 \\
Adjusted $R^{2}$ & .304 & .303 & .241 & .230 & .148 & .185 \\
$N$ & 412 & 412 & 412 & 412 & 412 & 412 \\
\hline
\end{tabular}

\section{Discussion}

From the model 3 in Table 3, we can see that Agreeableness*Stressor (work) is a negative predictor for the physiological stress response, which means interaction term of stressor (work) and agreeableness can negatively predict physiological stress response. That is to say, individuals high in agreeableness are less likely to be affected by work stress physiologically, while those low in agreeableness would be more likely to suffer from work stress physiologically. In another word, agreeableness is a protective factor for the physiological health in consideration of work stress and those who are less agreeable are more vulnerable to work stress physiologically.

From the model 4 in Table 3, we can see that Agreeableness*Stressor (health) is a negative predictor for the physiological stress response, which means interaction term of stressor (health) and agreeableness can negatively predict physiological stress response. That is to say, individuals high in agreeableness are less likely to be affected by health problem or health stress physiologically, while those low in agreeableness would be more likely to suffer from health stress physiologically. In another word, agreeableness is a protective factor for the physiological health in consideration of health stress and those who are less agreeable are more vulnerable to health stress physiologically.

From the model 5 in Table 3, we can see that Agreeableness*Stressor (family) is a negative predictor for the physiological stress response, which means interaction term of stressor (family) and agreeableness can negatively predict physiological stress response. That is to say, individuals high in agreeableness are less likely to be affected by family stress physiologically, while those low in agreeableness would be more likely to suffer from family stress physiologically. In another word, agreeableness is a protective factor for the physiological health in consideration of family stress and those who are less agreeable are more vulnerable to family stress physiologically.

From the model 6 in Table 3, we can see that Agreeableness*Stressor (social) is a negative predictor for the physiological stress response, which means interaction term of stressor (social) and agreeableness can negatively predict physiological stress response. That is to say, individuals high in agreeableness are less likely to be affected by social stress physiologically, while those low in agreeableness would be more likely to suffer from social stress physiologically. In another word, agreeableness is a protective factor for the physiological health in consideration of social stress and those who are less agreeable are more vulnerable to social stress physiologically.

Agreeableness includes traits of trust, altruism, frankness, modesty and empathy. Individuals of high agreeableness are more enthusiastic, trusting and helpful. They are optimistic about human nature, believing in innate purity. As what we found in this study, agreeableness is a protective factor for the physiological health in consideration of all kinds of stress. Human interaction may contribute a lot for this result: individuals high in agreeableness generally have relatively better social support systems, and they will get more support in face of a stress event. Thus, they are more likely to get the resources needed to cope with stress. In addition, because individuals with high agreeableness hold a positive attitude towards humanity, they will remain relatively optimistic for the results when facing stressors. This may also be one of reasons for its protective effect in physiological stress response in face of stressor.

From the model 3 in Table 4, we can see that Extraversion*Stressor (work) is a negative predictor for the physiological stress response, which means interaction term of stressor (work) and extraversion can negatively predict physiological stress response. That is to say, individuals high in extraversion are less likely to be affected by work stress physiologically, while those low in extraversion would be more likely to suffer from work stress physiologically. In another word, extraversion is a protective factor for the physiological health in consideration of work stress and the introverts are more vulnerable to work stress physiologically.

From the model 4 in Table 4, we can see that Extraversion*Stressor (health) is a negative predictor for the physiological stress response, which means interaction term of stressor (health) and extraversion can negatively predict physiological stress response. That is to say, individuals high in extraversion are less likely to be affected by health problem or health stress physiologically, while those low in extraversion would be more likely to suffer from health stress physiologically. In another word, extraversion is a protective factor for the physiological health in consideration of health stress and the 
introverts are more vulnerable to health stress physiologically.

From the model 5 in Table 4, we can see that Extraversion*Stressor (family) is a negative predictor for the physiological stress response, which means interaction term of stressor (family) and extraversion can negatively predict physiological stress response. That is to say, individuals high in extraversion are less likely to be affected by family stress physiologically, while those low in extraversion would be more likely to suffer from family stress physiologically. In another word, extraversion is a protective factor for the physiological health in consideration of family stress and the introverts are more vulnerable to family stress physiologically.

From the model 6 in Table 4, we can see that Extraversion*Stressor (social) is a negative predictor for the physiological stress response, which means interaction term of stressor (social) and extraversion can negatively predict physiological stress response. That is to say, individuals high in extraversion are less likely to be affected by social stress physiologically, while those low in extraversion would be more likely to suffer from social stress physiologically. In another word, extraversion is a protective factor for the physiological health in consideration of social stress and the introverts are more vulnerable to social stress physiologically.

The extraverts tend to be sociable, confident, optimistic, passionate and talkative. As what we found in this study, extraversion is a protective factor for the physiological health in consideration of all kinds of stress. Several reasons may be explainable for this result: Firstly, the extraverts are more likely to energetic comparing with their introvert counterparts, which may be a kind of immune for the stress. Secondly, the extraverts are more stimulate-seeking comparing with their introvert counterparts. It would made minor stressor not that unpleasant which in turn saved more mental capacity to the major stressor in their lives, which leads to more effective coping results.

\section{Conclusion}

By a comprehensive exploration of effects of agreeableness, extraversion and stressor on physiological stress response, the study obtained following conclusions:

- The interaction term of stressor (work) and agreeableness can negatively predict physiological stress response.

- The interaction term of stressor (health) and agreeableness can negatively predict physiological stress response.

- The interaction term of stressor (family) and agreeableness can negatively predict physiological stress response.

- The interaction term of stressor (social) and agreeableness can negatively predict physiological stress response.

- The interaction term of stressor (work) and extraversion can negatively predict physiological stress response.

- The interaction term of stressor (health) and extraversion can negatively predict physiological stress response.

- The interaction term of stressor (family) and extraversion can negatively predict physiological stress response.

- The interaction term of stressor (social) and extraversion can negatively predict physiological stress response.

\section{Reference}

Amin Z, Constable, R. T., Canli, T. H. (2004).Attentional bias for valenced stimuli as a function of personality in the dot-probe task. Journal of Research in Personality, 38(1), 15-23. http://dx.doi.org/10.1016/j.jrp.2003.09.011

Bakker, A. B, Zee, K.V. D., \& Lewig KA, et al. (2006).The Relationship Between the Big Five Personality Factors and Burnout: A Study Among Volunteer Counselors [ J ]. The Journal of Social Psychology, 146(1), 31-50. http://dx.doi.org/10.3200/socp.146.1.31-50

Canli T, Zhao, Z., Desmond, E. J., Kang, E., Gross, J., \& Gabrieli, J. D. E. (2001).An fMRI Study of Personality Influences on Brain Reactivity to Emotional Stimuli. Behavioral Neuroscience, 115(1), 33-42. http://dx.doi.org/10.1037/0735-7044.115.1.33

Cao Q, et al. (2006). Abnormal neural activity in children with attention deficit hyperactivity disorder: A resting-state functional magnetic resonance imaging study. Neuroreport, 17(10), 1033-1036. http://dx.doi.org/10.1097/01.wnr.0000224769.92454.5d

Costa, P. T, \& McCrae, R. R. (1980).Influence of extraversion and neuroticism on subjective well-being: Happy and unhappy people. Journal of Personality and Social Psychology, 38, 668-678. http://dx.doi.org/10.1037//0022-3514.38.4.668

Costa, P. T, \& McCrae, R. R. (1990). Personality disorders and the five-factor model of personality. Journal of Personality Disorders, 4(4), 362-371. http://dx.doi.org/10.1037/13939-001

Costa, P. T., \& McCrae, R. R. (1992). Revised NEO Personality, Inventory and NEO Five-Factor Inventory: Professional manual. Odessa, FL: Psychological Assessment Resources. 
De Neve, E. M., \& Cooper, H. (1998). The Happy Personality: A Meta-Analysis of Personality and Well-being. Psychology Bulletin, 2, 197-229

Derryberry, D, \& Reed, M. A. (1994).Temperament and attention: Orienting toward and away from positive and negative signals. Journal of Personality and Social Psychology, 66(6), 1128-1139. http://dx.doi.org/10.1037/0022-3514.66.6.1128

Hettler, T. R. (2001). Agreeableness and affective reactions to daily interpersonal stressors: Role of appraisals and specific coping strategies. ProQuest Information \& Learning.

Huang, Y. X, \& Luo, Y. J. (2007). Attention shortage resistance of negative stimuli in an implicit emotional task. Neuroscience Letters, 412(2), 134-138. http://dx.doi.org/10.1016/j.neulet.2006.10.061

Huang, Y. X., \& Luo, Y. J. Temporal course of emotional negativity bias: An ERP study. Neuroscience Letters, 2006, 398(1), 91-96. http://dx.doi.org/10.1016/j.neulet.2005.12.074

Jeffrey, B. D, \& Jaak, P.(2005). The neurobiology of positive emotions. Neuroscience and Biobehavioral Reviews, 2006, 30, 173-187. http://dx.doi.org/10.1016/j.neubiorev.2005.06.001

Chu, X. Y., Fan, F. Q., Li, Y., Han, J., \& Han, K. (2014) Social Capital, Socioeconomic Status and Self-efficacy. Applied Economics and Finance, 1(2), 1-10. http://dx.doi.org/10.11114/aef.v2i1.607

Lee $\mathrm{JH}$, et al. A functional magnetic resonance imaging (FMRI) study of cue -induced smoking craving in virtual environments. Applied Psychophysiology and Biofeedback, 30(3), 195-204. http://dx.doi.org/10.1007/s10484-005-6377-z

McCrae, R. R., \& John, O. P. (1992).An introduction to the five factor model and its applications. Journal of Personality, 60, 175-215. http://dx.doi.org/10.1111/j.1467-6494.1992.tb00970.x

Mills, L. B, \& Huebner E S. (1998) A Prospective Study of Personality Characteristics, Occupational Stressors, and Burnout among School Psychology Practitioners, Journal of School Psychology, 36(1), 103-120. http://dx.doi.org/10.1016/s0022-4405(97)00053-8

Ryan, J., Sheu, P. L., Gianaros, K., \& Peter, J. (2011). Resting state functional connectivity within the cingulate cortex jointly predicts agreeableness and stressor-evoked cardiovascular reactivity. NeuroImage, 55(1), 363-70. http://dx.doi.org/10.1016/j.neuroimage.2010.11.064

Schneider, T. R., Rench, T., Lyons, A., Joseph, B., Riffle, R. (2012). The influence of neuroticism, extraversion and openness on stress responses. Stress and Health: Journal of the International Society for the Investigation of Stress, 28(2), 102-110. http://dx.doi.org/10.1002/smi.1409

Tobin, R., Graziano, M., William, G., Vanman, Eric J., \& Tassinary, Louis G. (2000). Personality, emotional experience, and efforts to control emotions. Journal of Personality and Social Psychology, 79, 656-669. http://dx.doi.org/10.1037/0022-3514.79.4.656

Chu, X. Y., Fan, F. Q., Li, Y., Han, J., \& Han, K. (2015) Effects of Stressor and Personality Trait on Stress Response. Research in World Economy, 6(2), 1-11. http://dx.doi.org/10.5430/rwe.v6n2p

Yuan, J. J., Li, H., Chen, A. T., \& Luo, Y. J. (2007). Neural correlates underlying humans' differential sensitivity to emotionally negative stimuli of varying valences: an ERP study. Progress in natural science, 17(13), 115-121

Yuan, J. J., Zhang, Q. L., Chen, A. T., Li, H., Wang, Q., Zhuang, Z. C. X., \& Jia, S. W. (2007).Are we sensitive to valence differences in emotionally negative stimuli? Electrophysiological evidence from an ERP study. Neuropsychologia, 45(12), 2764-2771. http://dx.doi.org/10.1016/j.neuropsychologia.2007.04.018

\section{(cc) $\mathrm{Er}$}

This work is licensed under a Creative Commons Attribution 3.0 License. 